\title{
Research on the Teaching Method System of the Course of Computer Composition Principle Based on the Innovation Ability Training
}

\author{
Xiufang Li ${ }^{*}$ \\ College of Information, Qilu University of Technology (Shandong Academy of Sciences) Daxue Road, \\ Changqing District, Ji'nan, China \\ carol_xiufang@163.com \\ *corresponding author
}

Keywords: Innovation Ability Training, Teaching Method, Micro-course, Personnel Training, Computer Composition Principle

\begin{abstract}
As a core compulsory course of computer major, Computer Composition Principle has proposed higher requirement for practical ability. Based on educational idea of innovation ability training, by introducing new technologies and methods, this paper carries out a series of reform and innovation on course teaching methods and builds an innovation ability training system based on teaching method system, so as to be able to improve teaching quality and realize students' individualized learning and raise their innovation ability. With strong practicability and applicability, this system reflects development law of higher education and provides computer major teaching of college with a new thought and a new mode.
\end{abstract}

\section{Introduction}

Computer Composition Principle is a core compulsory course of computer science and technology major and a basic course of hardware course. Its teaching objectives are helping students establish concept of "complete machine" and making students have basic skills and methods of hardware analysis and design, through systemically introducing the composition of computer and the working principle of all its components, so as to help students lay a firm foundation for carrying out digital system advanced design.

\section{Teaching Idea}

Because this course has the characteristics of abstract concept and wide knowledge range, students' perceptual knowledge is poor, and their practical ability is high. It is difficult to achieve teaching goals by traditional teaching methods and teaching means. Therefore, training the students' practical ability and innovation ability is the primary problem in the current course teaching. First of all, we should emphasize the "student oriented", the knowledge system and the teaching process take the student as the center, and cultivate the students' basic cognition of the hardware system. Secondly, the rational design of the experimental content, theory and practice, so that students from the middle school, training their ability to analyze and solve problems. Finally, based on the demand of social posts, the theoretical knowledge system and experimental projects are expanded to cultivate their innovative and entrepreneurial ability.

\section{Curriculum Teaching Method System Based on Innovation Ability Training}

\subsection{Assist Classroom Teaching with Micro-course, and Practice Teaching Mode Combining Online and Offline}

With the rapid development of computer technology and electronic technology, the internal structure of computer is getting increasingly complex, enormous and highly integrated, which makes students all feel the course of Computer Composition Principle has large knowledge capacity 
and that it is difficult to learn and understand. Nevertheless, it is a main course for taking graduate exam and is very important. How to make students better familiarize and master basic knowledge and grasp key and difficult points of content becomes a pain spot of teaching, fortunately, the appearance of micro-course can solve this problem.

Teaching application of micro-course has the following three advantages:

First: Taking micro-video as main carrier, micro-course can change abstract and complex concept into visual and perceptual knowledge so as to not only reduce the learning difficulty of complex concept but also raise students' attention and interest to learning:

Second: Mostly, micro-course learning means carrying out full-load learning on only one "knowledge point", so it won't make students spend too much time and energy leaning;

Third: It is easy for teachers to organize teaching materials on "knowledge point" and organize online teaching real-time assessment and feedback more accurately.

The course refines all the key and difficult points in teaching content into several knowledge points and make exercises of each knowledge point and each key point into micro-course content; currently, 20 micro-videos of knowledge points and 14 exercise explaining videos have been completed. Then, place all the micro-videos along with their corresponding teaching resources (such as teaching courseware, teaching design etc) onto the network teaching platform. Students can carry out independent learning and independent testing after class; they can easily master those key points of knowledge and difficult questions through watching video again and again, especially when they have fewer class hours; in this way, classroom teaching is complemented and good teaching effect is reached.

\subsection{Diversify Classroom Teaching Mode to Ensure Teaching Quality}

Adopt various forms to combine boring theory knowledge with flexible practical application and form smooth information flow between teachers and students, so as to drive students' initiative, build active and humorous classroom teaching atmosphere and improve teaching quality.

\subsubsection{Heuristic Teaching Method}

When giving a lesson, consciously raise some phenomena or questions to guide students to think. For example, when explaining summator, guide students to think about: since ALU inside has summater, does it have subtracter? The teacher further guides: what's the meaning of complement occurrence? How does complement change into addition from subtraction? Through heuristic guiding, students connect organically two knowledge points looking like separating from each other so as to form complete knowledge system.

\subsubsection{Analogy teaching Method}

During giving a lesson, carry out connection and analogy of some concept, strategies and thoughts with vivid examples in real life so as to make students more easily understand and master teaching content and grasp key idea.

\subsubsection{Combine Traditional Board Writing Teaching with Multimedia Teaching}

Make full use of modern multimedia method; when having class, by means of multimedia courseware, make students acquire a visual and perceptual cognition and enlarge their knowledge scope. Multimedia courseware has diverse forms and vivid content so as to make students acquire perceptual knowledge visually and deepen their understanding and memory on theory knowledge. However, as to some computing exercises, aid of blackboard is needed to make students really master problem solving process and thinking.

\subsubsection{Case Teaching and Physical Display}

Cases which students are familiar with are used to further unfold the knowledge points being difficult to understand to help students understand. Introduce a great many of pictures, real objects and videos to carry out aid teaching, help students visually learn the external characteristics and structure of electronic element and meanwhile enrich their view. 


\subsection{Timely Update Knowledge System and Reasonably Organize Teaching Content}

The rapid development of computer technology and the discordant publication cycle of teaching materials make part of knowledge in teaching materials become older or outdated, which is also one of the reasons causing students to have less interest in learning. Therefore, the course team has made the three-dimensional teaching resources of course, newly compiled teaching program and experimental teaching program, compiled one copy of computer composition principle teaching materials, and developed multimedia courseware, micro-course video set and question bank. We need make more introduction on the latest technologies and new components during teaching to enable students to not only acquire theory knowledge but also open up their eyes and acquire practical knowledge, so as to improve their learning enthusiasm effectively.

Teaching content should be arranged based on the teaching program in such a way that it is properly detailed and concise, with the key points standing out. Because students mainly need to master the basic composition and working principle of computer ALU, storage, controller and I/O, more energy should be spent on the computing principle and composition mechanism of ALU, the composition and storage principle of various storages and the mechanism of microprogram controller, with a purpose to make students understand and master such knowledge; for other parts, depending on class hour number, make students learn by themselves, make brief explanation, or make discussion.

\subsection{Make Use of MOOC Platform and Smartphone APP and Explore New-type Flipped Classroom Teaching Method}

With popularization of information technology, MOOC and flipped classroom teaching become hot spots of teaching reform. MOOC platform concentrates a great number of free quality teaching resources and realizes the fullest sharing of education resources. Relying on MOOC platform of China universities, the course of Computer Composition Principle creates SPOC and actively practices flipped classroom teaching methods. Students can carry out individualized learning through online learning, in-class discussion and after-class testing and other links, so as to greatly improve teaching effect. Because smartphone features high popularization, portability and intelligence, in order to better practice idea of "innovation education", the course applies smart portable device in teaching to explore new-type flipped classroom teaching methods. By means of phone APP, the course carries out teaching activities such as attendance checking, question asking, brainstorming, grouping homework, classroom testing and questionnaire survey and sets up "mobile cloud classroom", so as to guide students to participate actively, think diligently and take action boldly, dig students' potential as much as possible, and realize innovation ability training.

\subsection{Introduce New Technologies in Practical Teaching, Combine Virtual Things with Reality, and Emphasize Innovation Ability Training}

The experimental facilities of traditional hardware course have low cost, poor function, small experimental difficulty and less variety and so they can't exercise and improve students' practice ability. The fact that students can't launch independent design and comprehensive design goes against cultivation of computer hardware thinking. The course experiment uses EDA (Electronic Design Automation) technology and carries out hardware circuit design using software, avoiding both the problem of electronic element cost and loss and the restriction of laboratory environment. This way turns hardware experiment into "design and innovation" type from "verification" type; the experimental process uses task-driven method and project-driven method to encourage students to innovate, which helps students give play to their independent innovation ability in a better way and lay a good foundation for engaging in complex hardware design.

\subsection{Actively Carry Out Teaching Research, Promote Learning with Contest and Promote Teaching with Contest}

"Making each class have good effect" is the goal of each teacher. When carrying out teaching activity, by combining social demand and the development trend of higher education, constantly 
summarize course teaching mode and teaching methods, blend information technology in teaching, and launch teaching research depending on teaching and research projects. Directing at the teaching of Computer Composition Principle, we have hosted many teaching and research projects of college and carried out exploration and practice on network individualized learning, practical learning and flipped classroom, and published many papers on teaching and research. Actively participate in teaching contest, teaching conference and teaching training and raise teaching ability while learning and mirroring peer experience. Contest is the best means of improving students' learning initiative and innovation ability. Actively guide students to take part in domestic and overseas contests because contests can make students better apply theory knowledge in practice and really learn industry demand and cutting-edge academic knowledge, so as to cultivate their innovation ability.

\subsection{Pay Attention to Teaching Feedback and Build Diverse Assessment Mechanism}

Teaching feedback is an important teaching link, by which teachers can not only assess students' usual results but also master their learning situation from time to time so as to revise teaching scheme in a timely way; meanwhile, it also helps improve teachers' self-professional level to reach the effect of "teaching is learning". Teaching feedback forms mainly include classroom question asking, discussion, after-class question answering, homework and experimental report and so on. By means of teaching feedback, the questions of students can be solved, and meanwhile teachers can benefit a lot from it.

With the society making progress, students' ideology is gradually changing, which requires teachers to transform assessment idea, respect students, fully dig their potential, give play to their advantages, affirm every piece of progress of students and every flashing point on their body, and build diverse assessment mechanism. Set question asking and testing links in classroom teaching, timely master students' dynamic, and reckon scores in examination system. Build experimental ability examination system, take experimental process and experimental works as checking emphases to reckon them in usual results and increase their proportion in usual results, so as to urge students to actively carry out practice and innovation.

\section{Teaching Effectiveness}

According to the characteristics of " Computer Composition Principle " course difficult to learn, understand, teach and practice capability is high, the teaching team to introduce new technology and new methods of teaching methods to conduct a series of reform and innovation, after years of practice, to construct a system of teaching methods based on multidimensional innovation ability of stereo. Practice has proved that the teaching method system can not only achieve students' personalized learning, improve teaching quality, but also help train students' professional quality and innovation ability. The system integrates new technologies and new methods, reflects the current development rule of higher education, and has strong practicability and applicability. It provides a new idea for the teaching of computer specialty in colleges and universities.

\section{Acknowledgements}

This paper has been funded by the Shandong province teaching and research project (NO. Z2016M018) and the education research project of Qilu University of Technology (NO.201662, NO.041201034116).

\section{References}

[1] Fan Jianli, Fang Huiping. (2016)"Internet Plus" Ara of the Micro-class Development Strategy and Application. Journal of Distance Education, 3, 104-106.

[2] Hu Tiesheng. (2014) Analysis and Development Countermeasures of the Construction of Microclass in Colleges and Universities. Modern Educational Technology, 2, 5-13. 
[3] Zhu Ping, Fan Jianli. (2015) Reflection on the Reform of Curriculum Teaching in China's Colleges and Universities in the Post MOOC Period. Journal of Changchun University, 12, 88-92.

[4] Jiang Zhuoxuan, Zhang Yan, Li Xiaoming. (2015) Analysis and Prediction of Learning Behavior Based on MOOC Data. Research and Development of Computer, 3, 614-628.

[5] Zhu Shouye. (2008) Curriculum Design and Learning Model for Mobile Learning. China Electrification Education, 12, 67-70. 